\title{
Benign Esophageal Neoplasm
}

National Cancer Institute

\section{Source}

National Cancer Institute. Benign Esophageal Neoplasm. NCI Thesaurus. Code C3598.

A non-metastasizing neoplasm arising from the esophageal wall. 